AperTO - Archivio Istituzionale Open Access dell'Università di Torino

\title{
Surface reactivity and in vitro toxicity on human bronchial epithelial cells (BEAS-2B) of nanomaterials intermediates of the production of titania-based composites
}

\section{This is the author's manuscript}

Original Citation:

Availability:

This version is available http://hdl.handle.net/2318/1561271

since 2016-06-17T12:07:37Z

Published version:

DOI:10.1016/j.tiv.2016.04.003

Terms of use:

Open Access

Anyone can freely access the full text of works made available as "Open Access". Works made available under a Creative Commons license can be used according to the terms and conditions of said license. Use of all other works requires consent of the right holder (author or publisher) if not exempted from copyright protection by the applicable law. 


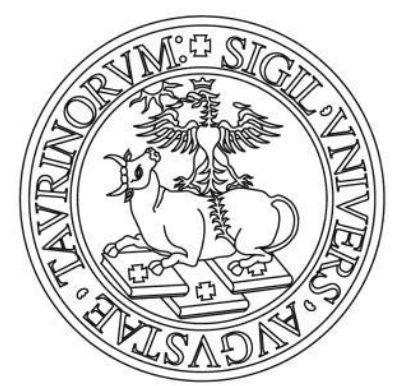

\section{UNIVERSITÀ DEGLI STUDI DI TORINO}

This is an author version of the contribution published on: Questa è la versione dell'autore dell'opera:

Surface reactivity and in vitro toxicity on human bronchial epithelial cells (BEAS-2B) of nanomaterials intermediates of the production oftitania-based composites

[Toxicology in Vitro 34 (2016) 171-178 DOI: 10.1016/j.tiv.2016.04.003] The definitive version is available at: La versione definitiva è disponibile alla URL: [http://www.journals.elsevier.com/toxicology-in-vitro/] 


\title{
Surface reactivity and in vitro toxicity on human bronchial epithelial cells (BEAS-2B) of nanomaterials intermediates of the production oftitania-based composites
}

\author{
Viviana Vergaro $^{\mathrm{a}, \mathrm{b}}$, Elisabetta Aldieri ${ }^{\mathrm{c}, \mathrm{d}}$, Ivana Fenoglio ${ }^{\mathrm{d}, \mathrm{e}_{*}}$, Arianna Marucco $^{\mathrm{d}, \mathrm{e}}$, Claudia Carlucci ${ }^{\mathrm{f}}$, \\ Giuseppe Ciccarella $\mathrm{a}^{\mathrm{a}, \mathrm{b}}$ *
}

${ }^{a}$ Biological and Environmental Sciences Department, University of Salento, Via Monteroni 73100 Lecce, Italy

${ }^{\mathrm{b}}$ Istituto di Nanotecnologia (NANOTEC) University of Salento, Via Monteroni 73100 Lecce, Italy

${ }^{\mathrm{c}}$ Department of Oncology, University of Torino, Italy

${ }^{\mathrm{d}}$ Department of Chemistry and NIS - Nanostructured Interfaces and Surfaces, University of Torino, Italy

e، 'G. Scansetti', Interdepartmental Centre for Studies on Asbestos and other Toxic Particulates, University of Torino, Italy,

${ }^{\mathrm{f}}$ Department of Chemistry, University of Bari, Via Orabona 4, 70126 Bari, Italy

Corresponding author:

IvanaFenoglio: Associate Professor of General and Inorganic Chemistry Department of Chemistry, University of Torino, via P. Giuria 7 10125-Torino Italy Tel. +39 116707506 e. mail:

ivana.fenoglio@unito.it

Giuseppe Ciccarella: Associate Professor Biological and EnvironmentalSciencesDepartment, University of Salento, Via Monteroni 73100 Lecce, Italy Tel. +39 0832298233 e.mail:giuseppe.ciccarella@unisalento.it 


\begin{abstract}
Titanium dioxide $\left(\mathrm{TiO}_{2}\right)$ nanoparticles (NPs) are manufactured worldwide in large quantities for use in a wide rangeof applications. Evaluating the hazards associated with $\mathrm{TiO}_{2} \mathrm{NPs}$ is crucial as it enables risk assessment related to human and environmental exposure. In this study the in vitro human toxicity of a set of $\mathrm{TiO}_{2}$ NPs modified with acetic, oleic and boric acids were studied in order to assess the hazard in view of a future scale-up of the synthesis. The surface reactivity of the powders under simulated solar illumination and in the dark has been evaluated by means of EPR spectroscopy. Human bronchial epithelial cells (BEAS-2B) have been chosen as a model for lung epithelium. Cytotoxicity has been assessed by measuring the cells membrane integrity by lactate dehydrogenase (LDH) assay, and the inflammatory response evaluated as nitric oxide (NO) and TNF- $\alpha$ production, and oxidative stress measured as intracellular reduced glutathione (GSH) levels, and induced lipoperoxidation. Aeroxide P25 was used for comparison.

The results demonstrated a low photoreactivity and a toxic effects lower than Aeroxide $\mathrm{P} 25$ of the nano- $\mathrm{TiO}_{2}$ powders, probably as a consequence of the presence of acidic moieties at the surface.
\end{abstract}

Keywords: $\mathrm{TiO}_{2}$, Cytotoxicity, Oxidative stress,Inflammation, Lung, Hazard. 


\section{Introduction}

In recent years there has been increasing evidence of the adverse effects related to the environmentalexposure to nanoparticles, such as the enhancement in respiratory and cardiovascular mortality and morbidity and worsening of asthma (Soto 2005; Chen 2006; Soto 2007; Warheit 2007).On the other hand, the riskassociated to the exposure to the growing number of engineered nanomaterials is poorly known. Many types of nanomaterials, such as silica, titanium dioxide $\left(\mathrm{TiO}_{2}\right)$, silver, carbon nanotubes, as well as some magnetic particles, have been investigated for their toxicity (Ray et al., 2009, Sharifi et al. 2012). Among them, $\mathrm{TiO}_{2}$ nanoparticles (NP) has received a great deal of attention due to their widespread use in several products (sunscreens, cosmetics, toothpaste, pharmaceuticals, paints, plastics, self-cleaning devices and food additives) that leads to a high human and environmental exposure. Model systems for lungs are largely employed in toxicologicalstudies since the respiratory tract is the main portal of entry of nanoparticles (Warheit, Borm et al. 2007; Park 2008). $\mathrm{TiO}_{2}$ NPs have been shown to be toxic in several in vitro models and to induce pulmonary inflammatory response (Oberdörster 2000; Oberdörster, Elder et al. 2009). However, the results are often controversial (Shi 2013), mainly as a consequence of the large variety of nanosized $\mathrm{TiO}_{2}$ commercial forms with different physicochemical characteristic savailable (Johnston 2009; Moschini 2013).

Many in vitro studies revealed cytotoxic, genotoxic and inflammatory effects induced by $\mathrm{TiO}_{2} \mathrm{NPs}_{\text {shat }}$ mediated by oxygenated reactive species (ROS) generation, apoptosis and DNA damage (Dunford, Salinaro et al. 1997; Park 2008; Shi 2010; Jugan 2012). Differences in toxic response elicited depending upon the crystalline form (anatase, rutile of mixed phase samples) of $\mathrm{TiO}_{2}$ or other physico-chemical properties such as particle sizeand shape, surface area, aggregation degree, agglomeration tendency and surface chemistry have been found (Bhattacharya 2009; Falck 2009; Johnston 2009; Xue 2010; Petkovic 2011).

Most of the nanotoxicological studies focus on commercial products or, when homemade, on the final products of syntheses. However, workers are exposed also to intermediates of the productions, which toxicity need to be therefore assessed.

Some of us previously reported the preparation of a series of nano-titania powders to be used as fillers in high-tech composites (Xu, Picca et al. 2013; Carlucci, Scremin et al. 2014; Carlucci, Xu et al. 2014; Carlucci, Xu et al. 2014; Xu, Carlucci et al. 2014).These materials were prepared via a microwavesolvothermal route using boric, acetic and oleic acid as the key additive reagents. The aim of this study was to assess the invitro human and ecotoxicity of the three kind of $\mathrm{TiO}_{2}$ nanopowders, in view of a future scaleup of the synthesis and, possibly, commercialization.

Illumination has been shown to play an important role in the ecotoxicity of $\mathrm{TiO}_{2}(\mathrm{Ma}$, Brennan et al. 2011; Clemente, Castro et al. 2014). $\mathrm{TiO}_{2}$ is in fact a photo-catalyzer, able to generate ROS that induce damage to aquatic species. Photo-activity has been here assessed by measuring the ability to produce free radicals under artificial solar light, to simulate the environmental conditions. As reference, a highly photo-reactive nano$\mathrm{TiO}_{2}$, the commercial mixed phase AeroxideP25 (Gerloff 2012) has been used. Furthermore, human bronchial epithelial cells (BEAS-2B), a cell line widely used as model to evaluate the toxicity of 
nanomaterials (Frohlich and Salar-Behzadi 2014), has been chosen to test the $\mathrm{TiO}_{2}$ intermediates for their potential human lung toxicity, being inhalation the main route of exposure of powders in occupational setting. Cytotoxicity has been assessed by measuring the cell membrane integrity by lactate dehydrogenase (LDH) assay, the occurrence of oxidative stress by evaluating lipoperoxidation (Malondialdehyde- MDA production) and the level of intracellular reduced glutathione (GSH), while the inflammatory response has been evaluated by measuring nitric oxide (NO) release and TNF- $\alpha$ production.

\section{Experimental section}

\section{Materials and Methods}

\section{$2.1 \mathrm{TiO}_{2}$ samples preparation}

All chemicals were analytical-grade reagents without further purification. In a typical synthesis procedure, 1 $\mathrm{mL}$ titanium tetraisopropoxide (TTIP) $(3.36 \mathrm{mmol})$ was slowly added into $10 \mathrm{~mL}$ of benzyl alcohol in a Teflon-line vessel. Acetic acid, oleic acid or boric acid were respectively added to the solution, without magnetic stirring.

The formed solution was then transferred into a Teflon vessel line (XP 1500) connected to a pressure transducer to monitor and control the pressure during the synthesis, under magnetic stirring. The microwaveassisted syntheses was conducted by using a microwave digestion system (Model. Mars, CEM, Matthews, NC). The system uses $2.45 \mathrm{GHz}$ microwaves and it is controlled by temperature $\left(210{ }^{\circ} \mathrm{C}\right)$ and pressure $(300$ psi).

The resulting product was collected and washed with methanol or diisopropylether at least three times in order to remove residues of the reaction and any by-products, and finally dried under vacuum at $50^{\circ} \mathrm{C}$ for 6 h. The different obtained samples were labelled as $\mathbf{A A}, \mathbf{A O}$ and $\mathbf{A B}$ respectively. The synthetic conditions were reported in table 1 .

Table 1. Synthetic conditions for the different samples.

\begin{tabular}{lccccccc}
\hline Sample & $\begin{array}{c}\text { Acetic Acid } \\
{[\mathbf{m m o l}]}\end{array}$ & $\begin{array}{c}\text { TTIP : AA } \\
\text { Ratio }\end{array}$ & $\begin{array}{c}\text { Oleic Acid } \\
\text { [mmol] }\end{array}$ & $\begin{array}{c}\text { TTIP : OA } \\
\text { Ratio }\end{array}$ & $\begin{array}{c}\text { Boric Acid } \\
\text { [mmol] }\end{array}$ & $\begin{array}{c}\text { TTIP : BA } \\
\text { Ratio }\end{array}$ & $\begin{array}{c}\text { Reaction } \\
\text { Time }\end{array}$ \\
\hline AA & 6.72 & $1: 2$ & & & & & $45^{\prime}$ \\
AO & & & 26.9 & $1: 8$ & & & $45^{\prime}$ \\
AB & & & & & 6.72 & $1: 2$ & 1 '30, \\
\hline
\end{tabular}

\subsection{Morphological Characterization}

Morphological characterizations of the $\mathrm{TiO}_{2}$ nanopowders were performed using conventional transmission electron microscopy (TEM). Images were obtained by using a JeolJem 1011 microscope operating at an accelerating voltage of $100 \mathrm{kV}$. The samples were prepared by dropping diluted solutions of titania nanoparticles in ethanol onto 400-mesh carbon-coated copper grids and immediately evaporating the solvent. Powder X-ray diffraction (XRD) for the phase analysis of the nanocrystals was performed with a Rigaku(Tokyo, Japan) RINT2500 diffractometer, using $\mathrm{Cu} \quad \mathrm{K} \alpha$ monochromatic radiation 
$(\lambda=1.5418 \AA)$. The XRD patterns were recorded in the range of $2 \theta=20^{\circ}-90^{\circ}$ by coupled $\theta / 2 \theta$ scanning mode, using $2 \theta$ increments of $0.03^{\circ}$. The XRD patterns were analyzed by using a whole-profile Rietveld-based fitting program (FULLPROF)(Wiles and Young 1981), according to the following procedure:

(1) The instrumental resolution function (IRF) wasevaluated by fitting the XRD pattern of a $\mathrm{LaB}_{6}$ NIST (National Institute of Standards and Technology) standard recorded under the same experimental conditions used for measuring the samples. The IRF data file was provided separately to the program in order to allow subsequent refinement of the XRD patterns of the samples.

(2) The phase composition of the samples was determined by fitting the XRD patterns with the crystal structure models of tetragonal $\mathrm{TiO}_{2}$ nanoanatase (Inorganic Crystal Structure Database \# 92363; space group: I41/amd; cell parameters: $a=b=3.77 \AA$ and $c=9.43 \AA ; \alpha=\beta=\gamma=90^{\circ}$ ). The weight percentage accuracy of the estimation was determined to be $5-7 \% \mathrm{w} / \mathrm{w}$;

(3) The inhomogeneous peak broadening of the anatase reflections was described by a phenomenological model based on a modified Scherrer formula:

$$
\beta_{h, k, l}=\frac{\lambda}{D_{h, k, l} \cos \theta}=\frac{\lambda}{\cos \theta} \sum_{\text {imp }} a_{i m p} Y_{\text {imp }}\left(\Theta_{h}, \Phi_{h}\right)
$$

where $\beta_{h, k, l}$ was the size contribution to the integral width of the $(h, k, l)$ reflection and $Y_{i m p}$ were the real spherical harmonics normalized according to a procedure described elsewhere(Jarvinen 1993). After refinement of the $a_{i m p}$ coefficients, the program calculated the coherent crystal apparent domain size along each reciprocal lattice vector $(h, k, l)$ direction. The other refinable parameters were the unit cell parameters. The background was unrefined and linearly interpolated.

The nitrogen adsorption-desorption isotherms at $77 \mathrm{~K}$ by Brunauer-Emmett-Teller (BET) characterization were recorded with a ASiQwin system(Quantachrome, Boynton Beach, FL, USA).

\subsection{Free Radical Generation}

The ability of a particle to generate radical species was monitored by electron spin resonance (ESR) spectroscopy (Miniscope 100 ESR spectrometer, Magnettech, Berlin, Germany) using the spin trapping technique with 5,5-dimethyl-1-pyrroline-N-oxide (DMPO) as trapping agent according to a procedure previously described(Fenoglio, Ponti et al. 2013).

Briefly, a suspension of $30 \mathrm{mg}$ of the $\mathrm{TiO}_{2}$ powders was diluted in $125 \mu \mathrm{l}$ buffered solution $(0.5 \mathrm{M}$ potassium phosphate buffer, $\mathrm{pH}$ 7.4) containing sodium formate (Sigma-Aldrich, St. Louis, MO) $2 \mathrm{M}$ (1 mM final concentration) and $125 \mu \mathrm{l}$ of DMPO 0.17M (40 mM final concentration). The suspension was stirred at room temperature in the dark (black vials) or under simulated solar light (500 W mercury/xenon lamp -Oriel Instruments- equipped with an IR water to avoid the overheating of the suspensions and a $400 \mathrm{~nm}$ cut-off filter).The ESR spectra were recorded directly on aliquots of the suspension within one hour. All experiments were repeated at least twice.

The experiments were conducted under simulated solar illumination (500 W mercury/ xenon lamp, Oriel Instruments, equipped with an infrared water filter to avoid the overheating of the suspensions and a $400 \mathrm{~nm}$ cut-off filter) and in the dark (incubation in a dark vials). 


\subsection{Dispersion of $\mathrm{TiO}_{2}$ samples in the Culture Media}

The $\mathrm{TiO}_{2}$ samples were suspended in the culture media described below at a concentration of $0,5 \mathrm{mg} / \mathrm{ml}$ in a eppendorf tube. The suspensions were sonicated for 1 min twice with a probe sonicator (Sonoplus, Bandelin, Berlin, Germany) with the following experimental setting:100 W, $20 \mathrm{kHz}$,attenuation 40\%, probe in titanium, diameter of the probe $13 \mathrm{~mm}$ ). The suspension was administered to the cell culture in reduced illumination conditions, i.e. by obscuring the hood to reduce illumination by indoor light thus avoiding photo-activation of the powders.

\subsection{Hydrodynamic diameter and $\zeta$-potential measurements}

$\mathrm{TiO}_{2}$-NP stability and tendency to aggregate in different aqueous media were investigated by dynamic light scattering and $\zeta$-potentialmeasurements. All samples $(0.5 \mathrm{mg} / \mathrm{ml}$ ) were suspended in aqueous solutions (either phosphate buffer saline solutions or cell culture medium) and dispersed according to the following protocol: (i) 1 min stirring, (ii), $30 \mathrm{sec}$-sonication (Elma Transsonic T460-H) (RO 5 power IKAMAH) and (iii) further 1 min stirring. The mean hydrodynamic diameter was calculated from the autocorrelation function of the intensity of light scattered from the particles. A Zetasizer apparatus (3000 HS, Malvern Instruments Ltd., UK) was employed on NP dispersions sufficiently diluted $(0.5 \mathrm{mg} / \mathrm{ml})$ to avoid multiple scattering. Experiments on all samples were repeated twice and data reported as average value \pm standard deviation repeated twice, and data will be reported as average value \pm standard deviation.

The electrophoretic mobility ( $\zeta$-potential measurements) of $\mathrm{TiO}_{2}-\mathrm{NP}$ aggregateswas measured at $\mathrm{T}=298 \mathrm{~K}$ by employing the Zetasizer apparatus described above and was automatically converted to $\zeta$-potential values, by means of the instrument software based on the Henry's equation with the Smoluchowski approximation. Z-potential value of each investigated sample will be reported as the mean of data obtained for five subsequent measurements performed on each of two independently prepared dispersions. Data are reported as mean values \pm standard deviation. The dispersion obtained by suspending $0.5 \mathrm{mg}$ of TiO2-NP per $\mathrm{ml}$ of aqueous solution was employed for the evaluation of isoelectric point (IEP) of the stable aggregates. Zpotential was determined in the $2.5-9.5 \mathrm{pH}$ range: $\mathrm{pH}$ was measured by means of a Mettler Toledo Seven Easy $\mathrm{pH}$-meter and adjusted to the desired value by using diluted $\mathrm{NaOH}$ and/or $\mathrm{HCl}$ aqueous solutions. Data are reported with an accuracy of less than $5 \%$ of error.

\subsection{Cells and Reagents}

Human bronchial epithelial (BEAS-2B) cells are immortalized cells obtained from American Type Culture Collection (ATCC, Manassas, VA). They were cultured in $35-\left(1.2 \times 10^{6}\right.$ cells) or $100-\left(7.5 \times 10^{6}\right.$ cells $) \mathrm{mm}$ diameter petri dishes in RPMI 1640 medium (Gibco, Paisley, UK) supplemented with $10 \%$ fetal bovine serum (FBS) and $1 \%$ penicillin/streptomycin in a humidified incubator at $37^{\circ} \mathrm{C}$ in a $5 \% \mathrm{CO}_{2}$ atmosphere.The generic cell culture protocol consisted of growing the cells in an incubator at $37^{\circ} \mathrm{C} 5 \mathrm{CO}_{2}$ in 75 or 150 $\mathrm{cm}^{2}$ flasks, replacing media every 2-3 days, and passaging before confluence by dislodging with trypsin, 
washing and seeding new dishes or treatment wells. Prior to the commencement of the assay, $\mathrm{TiO}_{2} \mathrm{samples}$ $\left(1-5-10 \mu \mathrm{g} / \mathrm{cm}^{2}\right.$ equal to $5-25-50 \mu \mathrm{g} / \mathrm{mL}$ ) were sonicated (100 W: $30 \mathrm{sec}$; LabsonicSonicator; Sartorius Stedim Biotech S.A., Aubagne, France) to allow better suspension in the culture medium. Cells were incubated for 24, 48 or $72 \mathrm{~h}$ in the absence or presence of $\mathrm{TiO}_{2}$. All biological experiments were performed in triplicate $(n=3)$. The protein content of the monolayers and cell lysates was assessed with the BCA kit from Pierce (Rockford, IL).

\subsection{Measurement of Leakage of Lactate Dehydrogenase (LDH) Activity}

The cytotoxic effect of $\mathrm{TiO}_{2}$ on cell membrane integrity was determined by measuring the activity of lactate dehydrogenase (LDH), released into the extracellular medium as a consequence of membrane damage (Polimeni, Gazzano et al. 2008). LDH assay is a marker of cell membrane integrity. After each incubation, extracellular medium was collected and centrifuged at 13,000 $\times \mathrm{g}$ for $30 \mathrm{~min}$. The cells (cultured in 35-mmdiameter petri dishes, $1.2 \times 10^{6}$ cells) were washed with fresh medium, detached with trypsin/ethylenediaminetetracetic acid (EDTA; 0.05/0.02\% v/v), washed with phosphate-buffered saline (PBS), resuspended in $1 \mathrm{ml}$ TRAP (82.3 mM triethanolamine, $\mathrm{pH}$ 7.6), and sonicated on ice with two 10-s bursts. Aliquots of cell lysate $(5 \mu \mathrm{l}, 2.5 \mu \mathrm{g}$ protein) and extracellular medium (50 $\mu \mathrm{l} / 2 \mathrm{ml}$ medium) were diluted with TRAP and supplemented with $0.5 \mathrm{mM}$ sodium pyruvate and $0.25 \mathrm{mM}$ NADH (final volume of the mix $300 \mu \mathrm{l}$ ) to start the reaction. The reaction was followed for $10 \mathrm{~min}$, measuring the absorbance at 340 nm $\left(37^{\circ} \mathrm{C}\right)$ with a Packard EL340 microplate reader (Bio-Tek Instruments, Winooski, VT). Each set of reaction kinetics was linear throughout the time of measurement. Both intracellular and extracellular enzyme activities were expressed as micromoles NADH oxidized per minute per dish, and then extracellular LDH activity (LDH out) was calculated as percent of total (intracellular + extracellular) LDH activity (LDH tot) in the dish.

\subsection{Measurement of Lipid Peroxidation}

Thiobarbituric acid-reactive substances (TBARS) assay was used to detect lipid peroxidation products according to Yano (Yano 1988). After $24 \mathrm{~h}$ of incubation in the absence or presence of different $\mathrm{TiO}_{2}$ concentrations, cells (cultured in 60-mm-diameter petri dishes, $2.5 \times 10^{6}$ cells) were washed with fresh medium, detached with trypsin/EDTA $(0.05 / 0.02 \%$, v/v), and resuspended in $1 \mathrm{ml} \mathrm{PBS}$. A $500-\mu 1$ aliquot of cell suspension, each containing the same amount of cell proteins $(0.1 \mathrm{mg})$, was added to $5 \mu 1$ Triton X-100 and $500 \mu \mathrm{TBA}$ solution $(0.375 \%$ thiobarbituric acid and 30\% trichloroacetic acid in $0.5 \mathrm{~N} \mathrm{HCl})$. Samples were boiled for $20 \mathrm{~min}$ at $100{ }^{\circ} \mathrm{C}$, rapidly cooled by immersion in an ice bath, and centrifuged for $30 \mathrm{~s}$ at $13,000 \times \mathrm{g}$. The absorbance of $300 \mu \mathrm{l}$ of the reaction mixture at $532 \mathrm{~nm}$ was read with a Packard EL340 microplate reader. TBARS values were expressed as picomoles per milligram cellular protein.

\subsection{Measurement of Intracellular Glutathione}


Intracellular reduced glutathione (GSH) was measured as previously described (Vandeputte, Guizon et al. 1994). Cells (cultured in 35-mmdiameter petri dishes, $1.2 \times 10^{6}$ cells) were washed with PBS, and $600 \mu 1$ $0.01 \mathrm{~N} \mathrm{HCl}$ was added to each cell monolayer. After scraping, the cells were frozen/thawed twice and proteins were precipitated by adding $120 \mu \mathrm{l}$ of $6.5 \% 5$-sulfosalicylic acid to $480 \mu$ lysate. Each sample was placed in ice for $1 \mathrm{~h}$ and centrifuged for $15 \mathrm{~min}$ at $13,000 \times \mathrm{g}(4 \circ \mathrm{C})$. Total $\mathrm{GSH}$ was measured in $20 \mu \mathrm{l}$ cell lysate $(15 \mu \mathrm{g}$ protein) with the following reaction mix: $20 \mu \mathrm{l}$ stock buffer $(143 \mathrm{mM} \mathrm{NaH} 2 \mathrm{PO} 4,63 \mathrm{mM}$ EDTA, pH 7.4), $200 \mu$ daily reagent (10 mM 5,5 dithiobis-2-nitrobenzoic acid [DTNB], $2 \mathrm{mM}$ NADPH in stock buffer), and $40 \mu \mathrm{l}$ glutathione reductase $(8.5 \mathrm{U} / \mathrm{mL})$. The kinetics of reaction was followed at $415 \mathrm{~nm}$ for 10 min (to check that it was linear) using a Packard microplate reader EL340. Each measurement was made in triplicate, and results were expressed as nanomoles GSH per milligram cellular protein.

\subsection{Measurement of Nitric Oxide Synthesis}

After a 24-h incubation, the extracellular medium was removed and tested for the content of nitrite, which is a stable derivative of nitric oxide (NO), using the Griess method as previously described (Ghigo, Aldieri et al. 1998). A blank was prepared in the absence of cells, and its absorbance was subtracted from the one measured in the samples; absorbance values were corrected for the content of cell proteins, and results were expressed as nmol/mg cellular proteins. Parallel cell-free controls containing different concentrations of particles were assayed to determine the potential interference of particles with the assay reagents.

\subsection{Measurement of Tumor Necrosis Factor- $\alpha$ Production}

After a 24-h incubation, the extracellular medium was collected and centrifuged at 13,000 $\mathrm{g}$ for $30 \mathrm{~min}$. The concentration of the cytokine in the supernatant was determined by using the Conventional ELISA kit from Bender MedSystems (Vienna, Austria), following the manufacturer's instructions. Absorbance was measured at $450 \mathrm{~nm}$ with a Synergy HT microplate reader. The cytokine amount, corrected for the content of cell proteins, was expressed as $\mathrm{pg} / \mathrm{ml} / \mathrm{mg}$ cellular proteins. Parallel cell-free controls containing different concentrations of particles were assayed to determine the potential interference of particles with the assay reagents.

\subsection{Statistical analysis}

Statistical analysis was carried on results obtained from three fully independent experiments, while measures concerning each experiment were performed in duplicate or triplicate, according to the test used. All results were evaluated using one-way analysis of variance (ANOVA) with Dunnett's post-hoc comparison. Data shown in the graphs represent mean and standard deviations (SD), with level of significance indicated by the number of asterisks, the $95 \%$ confidence $(\mathrm{p}<0.05)$ was considered significant. Statistical analyses were performed using GraphPad Prism 6 Software.

\section{Results}




\section{1 $\mathrm{TiO}_{2}$ nanoparticles characterization}

$\mathrm{TiO}_{2}$ nanocrystals in anatase phase were synthesized via a microwave-solvothermal route using TTIP as the precursor, benzyl alcohol as the solvent, and acetic, boric and oleic acid as the key additive reagents. This is a simple, economical method that produces highly replicable results and affords the opportunity to control the morphology and dimensions of nanometric, anatase-phase $\mathrm{TiO}_{2}$ particles in a single step. The products, obtained without recourse to any subsequent treatment, have high anatase content, nanocrystalline-scale particle dimensions and a predominant shape. Moreover, the new method of preparation is carried out in the absence of surfactants, additional templants or other additives, thus reducing the possibility for the occurrence of phase precipitations or separations and presence of organic impurities(Xu, Picca et al. 2013; Carlucci, Scremin et al. 2014; Carlucci, Xu et al. 2014; Carlucci, Xu et al. 2014; Ciccarella Giuseppe 2014; $\mathrm{Xu}$, Carlucci et al. 2014).

TEM images (figure 1, table 2) revealed differently-shaped nanocrystals. Aeroxide $\mathrm{TiO}_{2} \mathrm{P} 25$ is a commercial product made by pyrolysis, and consisting of $80 \%$ of anatase crystal phase and $20 \%$ of rutile.Its physicalchemicalnature has been reported in several studies. However, small differences in morphology and crystallinitymay be encountered depending upon the batch used.Figure 1 show that the nanoparticles used in this study present an irregular faceted morphology and an average diameter size of about $30 \mathrm{~nm}$. Sample AA have a nearly spherical or slightly elongated shape with the diameter of the nanoparticles increasing in the longitudinal side, with an average size between $2 \mathrm{~nm}$ and $7 \mathrm{~nm}$ (figure 1 (b)). Sample AB (figure 1 (c)) revealed an estimated average size for the short axis of about $5-6 \mathrm{~nm}$, and of $7-8 \mathrm{~nm}$ for the long axis. Sample AO (figure 1 (b)) consisted of nanorods with an estimated average size between $3 \mathrm{~nm}$ (diameter) and $33 \mathrm{~nm}$ (length). The measured surface area (Table 1) well agrees with the different dimension of the primary particles.XRD analysisrevealed that all prepared nanomaterials were anatase (Table 1).
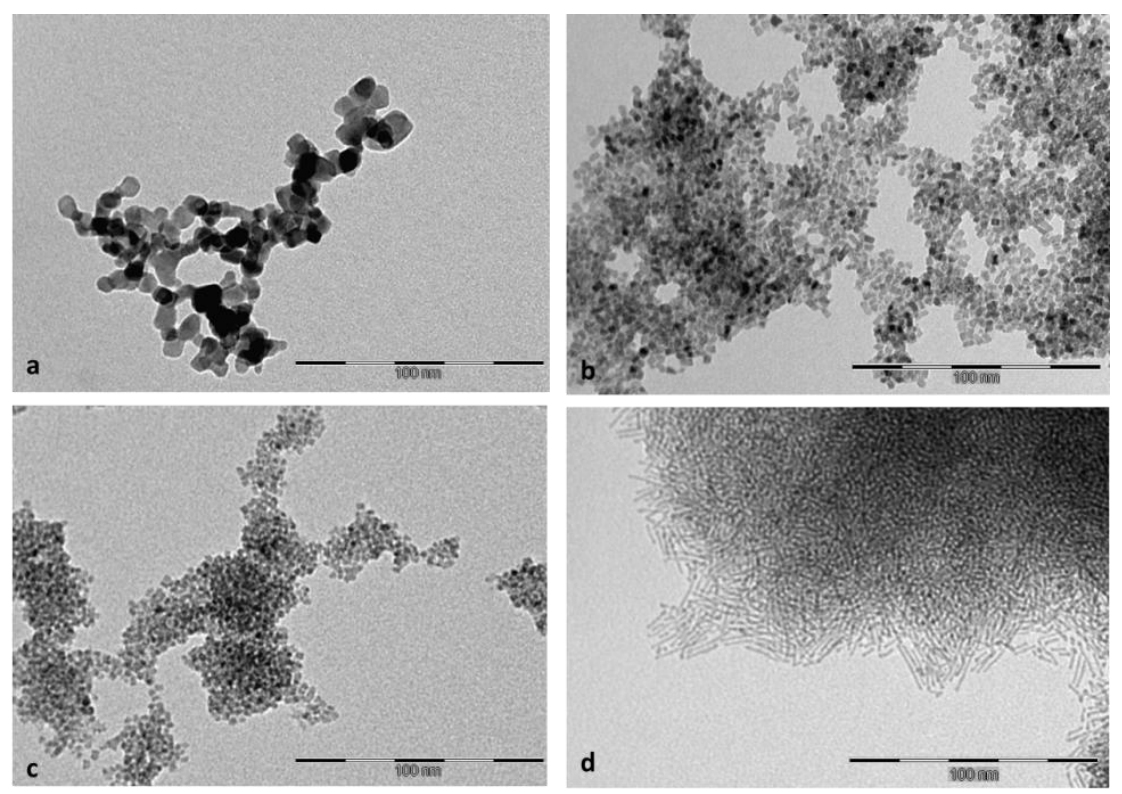

Figure 1.TEM images acquired of different $\mathrm{TiO}_{2}$ samples: (a) Aeroxide P25, (b) AA, (c) AB (d) AO. Scale bar $100 \mathrm{~nm}$. 
The organic acids used in the synthesis coordinate on the titania surface and provide a layer which has characteristic bands in the FT-IR spectrum. $\mathrm{TiO}_{2}$ surface characterization was detected by the FT-IR spectra, as described in our previous works (Carlucci, Xu et al. 2014; Carlucci, Xu et al. 2014; Ciccarella Giuseppe 2014). In the FT-IR spectrum of the of $\mathrm{TiO}_{2}$-TBsamples (see SM figure SM2), the absorption peak at $1397 \mathrm{~cm}^{-1}$ can be ascribed to the vibration of tri-coordinated boron. Furthermore, absorption peaks at 1202 and $1096 \mathrm{~cm}^{-1}$ could be attributed to pure $\mathrm{B}_{2} \mathrm{O}_{3}$ and incorporated $\mathrm{BO}_{4}$ which reveal the increase of boron content. These results show that boron is probably introduced into the titania framework in the form of Ti-OB bond.

Characterization of the nanomaterials in cell media is a prerequisite for accurate toxicological tests (Prasad 2013),(Jiang, Oberdörster et al. 2009). The aggregates/agglomerates size may be qualitatively assessed by measuring the hydrodynamic diameter of the particles/agglomerates by means of Dynamic Light Scattering (DLS), while the surface charge may be indirectly estimated by measuring the $\zeta$-potential.

The stability of $\mathrm{TiO}_{2}$ NP dispersions were monitored first in ultra-pure water, then in phosphate buffer solution (PBS) and then in culture medium (see SM figure SM1).In ultra-pure water all $\mathrm{TiO}_{2} \mathrm{NPs}$ exhibited $\zeta$-potential values that vary depending upon the $\mathrm{pH}$; as expected, an acidic point of zero charge (PZC) was found for the $\mathrm{TiO}_{2}$ samples likely due to the presence of acidic species at the surface, i.e. acetic acid, boric acid and oleic acid used to synthesize them. In PBS, and especially in culture medium, the $\zeta$-potential values decreased for all samples and the curves became similar, due to both an increaseionic strengths and to the adsorption of phosphate buffer and proteins (Marucco, Turci et al. 2013; Marucco, Catalano et al. 2015).With regard to stability and aggregation, in RPMI at physiological pH, all samples exhibited a similar mean size and dispersion degree, with poly dispersion index (PDI) relatively high but smaller than P25. These differences encountered among samples and P25 should not be attributed to a different repulsion

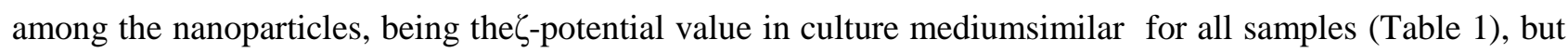
likely a consequence of a reduced aggregation degree due to the different methods of synthesis .

\begin{tabular}{|c|c|c|c|c|c|}
\hline Sample & $\begin{array}{c}\text { Crystalline } \\
\text { Phase }^{\mathrm{a}}\end{array}$ & $\begin{array}{l}\text { Mean Size } \\
(\mathrm{TEM}) \mathrm{nm}\end{array}$ & $\begin{array}{l}\text { Surface area } \\
\text { BET }\left(\mathrm{m}^{2} / \mathbf{g}\right)^{\mathbf{b}}\end{array}$ & $\begin{array}{c}\text { Mean size } \\
\text { in RPMI } \\
\text { (nm) /PDI) }\end{array}$ & $\begin{array}{c}\zeta \text { potential in } \\
\text { RPMI } \\
(\mathrm{mV}))\end{array}$ \\
\hline $\mathrm{P} 25$ & $\begin{array}{c}\text { Anatase } 80 \% \text {; } \\
\text { Rutile } 20 \%\end{array}$ & $\begin{array}{c}30 \pm 4 \text { (Anatase) } \\
50 \pm 6 \text { (Rutile) }\end{array}$ & 53.0 & $344,0 \pm 32,8 / 0.691$ & -8.0 \\
\hline $\mathrm{TiO}_{2}-\mathrm{AA}$ & Anatase $100 \%$ & 7 (lenght); 2(diam) & 140.3 & $188,8 \pm 4,4 / 0.310$ & -7.8 \\
\hline $\mathrm{TiO}_{2}-\mathrm{AB}$ & Anatase $100 \%$ & $7.0 \pm 0.9 ; 5.6 \pm 0,7$ & 136.0 & $222,7 \pm 9,2 / 0.235$ & -7.9 \\
\hline $\mathrm{TiO}_{2}-\mathrm{AO}$ & Anatase $100 \%$ & $33.3 \pm 12.5 ; 3$ & 60.2 & $232,4 \pm 0,3 / 0.357$ & -7.9 \\
\hline
\end{tabular}

Table 1. Main Physico-chemical properties of the samples. ${ }^{a}$ XRDmeasurements, ${ }^{b}$ BET measurements 


\subsection{Surface reactivity}

$\mathrm{TiO}_{2}$ is a photo-catalyst able to generate high amount of free radical species. This reactivity is clearly relatedto its photo-toxicity (Dunford, Salinaro et al. 1997; Fenoglio, Ponti et al. 2013) or ecotoxicity (Ma, Brennan et al. 2011), while the role of such reactivity in the dark is still under debate (Sayes, Wahi et al. 2006; Carlotti, Ugazio et al. 2009; Petkovic 2011). Some of us previously proposed a series of protocols that may be used to assess the surface reactivity of $\mathrm{TiO}_{2}$ (Corazzari, Livraghi et al. 2012; Fenoglio, Ponti et al. 2013). Among them, the generation of carboxyl radicals from sodium formate has been shown to be a reliable method to assess the overall oxidative capacity of $\mathrm{TiO}_{2}$. Oxidative reactions are, in fact, the most involved in the degradative processes induced by $\mathrm{TiO}_{2}$. The reactivity of the $\mathrm{TiO}_{2}$ samples has been evaluated firstly by performing the reaction under simulated solar illumination (Figure 2A). As expected an intense EPR spectra, corresponding to $\mathrm{CO}_{2}{ }^{\circ-}$ radicals trapped by the spin trap DMPO was recordedfor P25 suggesting an high amount of radical species generated(Fenoglio, Ponti et al. 2013). Since the samples exhibit an high surface area, andare made of pure anatase, a high photo-reactivity was expected. Conversely, a very small signal was observed for all samples suggesting that the presence of organic compounds or borate at the surface inhibitsthe oxidative photo-reactivity of the samples.

Since inhaled powders elicit their biological effect in the dark, the experiments were repeated by keeping the suspension in a black vial. A small reactivity was still observedfor P25 while the other samples appeared totally inert.
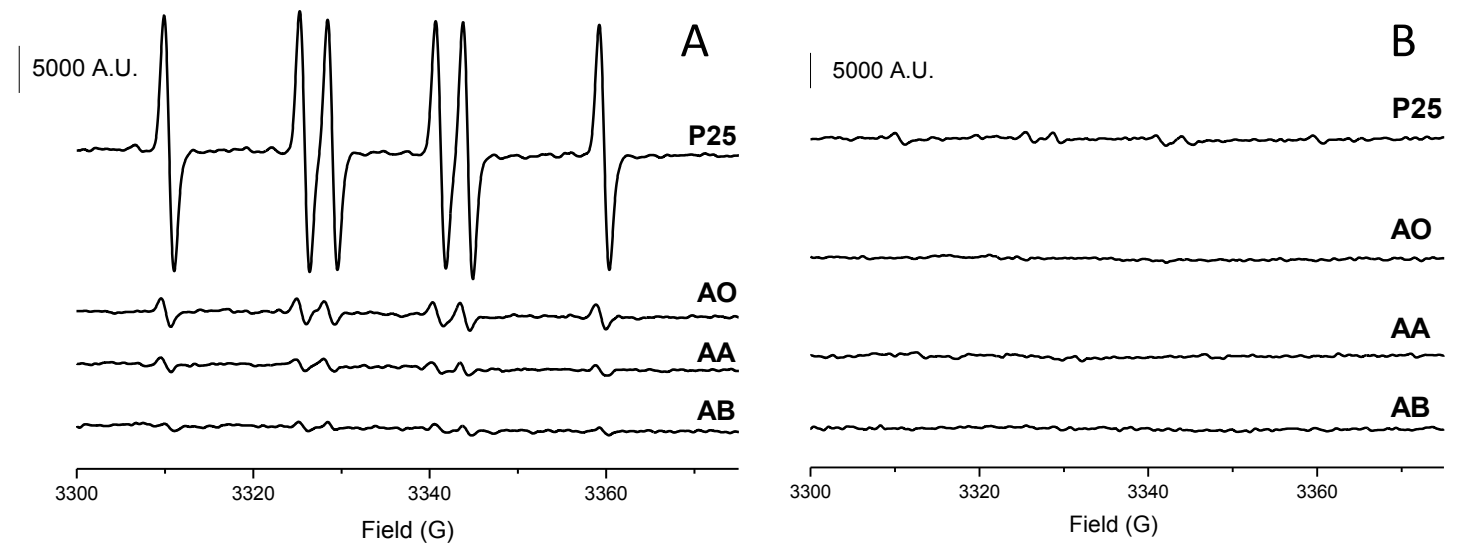

Figure 2. Surface reactivity of the $\mathrm{TiO}_{2}$ nanomaterials measured by means of EPR spectroscopy as ability to generate carboxyl radicals form sodium formate under A) simulated solar illumination and. B) dark. In the figure representative EPR spectra obtained in the various experiments are shown. The intensity is expressed in arbitrary units (A.U.)

\subsection{Cytotoxicity}

The prompt LDH release detected in the present study on BEAS-2B cells, beginning from $5 \mu \mathrm{g} / \mathrm{ml}$, correlates with the viability reduction and indicates cell membrane damage induction as a first step of the cytotoxic process, presumably followed by other events such as apoptosis induction, demonstrated by Park and Shi 
(Park 2008; Shi 2010). The $\mathrm{TiO}_{2}$ powders were tested for their toxicity toward BEAS-2B cells at very low doses $\left(1.0,5.0\right.$ and $10 \mu \mathrm{g} / \mathrm{cm}^{2}$ correspondent to $5 \mu \mathrm{g} / \mathrm{ml}, 25 \mu \mathrm{g} / \mathrm{ml}$ and $50 \mu \mathrm{g} / \mathrm{ml}$ respectively by measuring the membrane integrity by leakage of intracellular LDH into the extracellular medium. To assess the appropriate time for the incubation of BEAS-2B cells with $\mathrm{TiO}_{2}$ samples, time dependent experiments were performed (data not shown). As a consequence of these preliminary results, we evaluated LDH leakage after 72 hours of incubation with increasing concentration of titania nanoparticles as reported in Fig. 3.

A little cytotoxic effects were observed after cellular incubation with for the sample $\mathrm{AB}$ at the concentration of $25 \mu \mathrm{g} / \mathrm{ml}$ : however, all the other samples exerted no significant cytotoxic effects after cellular incubation with synthesized $\mathrm{TiO}_{2}$ nanoparticles, and did not induce significant $\mathrm{LDH}$ leakage after any time period of incubation. Conversely, even at the lowest tested dose, P25 induced a significant cytotoxicity.

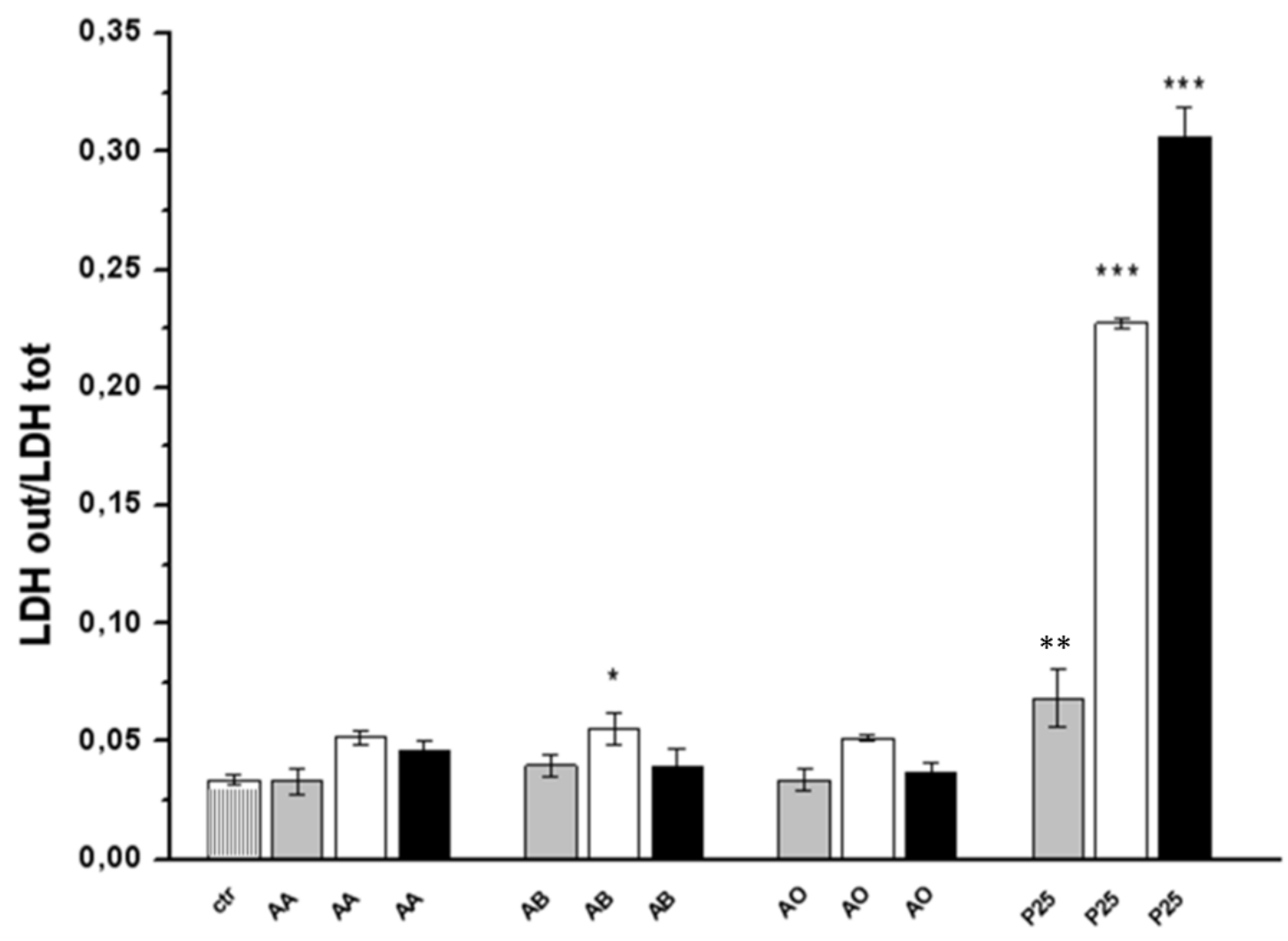

Figure 3: Effect of titanium dioxide nanoparticles on BEAS-2B cell membrane damage measured by the LDH assay. Cells were incubated with 1.0 (gray), 5.0 (white) and 10 (black) $\mu \mathrm{g} / \mathrm{cm}^{2}$ of the different $\mathrm{TiO}_{2}$ samples for 72 hours. Values are expressed as the mean \pm standard deviation of three independent experiments $(n=3)$. The $95 \%$ confidence $(\mathrm{p}<0.05)$ was considered significant vs control (straight line). ${ }^{*} \mathrm{p}<0.05$ was considered significant. vs respective control: ${ }^{*} \mathrm{p}<0,01 ;{ }^{* *} \mathrm{p}<0,001 ;{ }^{* * *} \mathrm{p}<0.0001$.

\subsection{Induction of inflammatory markers}

Nanoparticles have been shown to alter the redox homeostasis of cells and to induce inflammation(Foster, Galeffi et al. 2006; Park, Yi et al. 2008), $\mathrm{TiO}_{2}$ has been reported to lead to oxidative stress and to induce the release of inflammatory markers (Shi 2013), however the exact mechanisms are still unclear. 
The inflammatory response was assessed by measuring the extracellular levels of nitrite (the stable derivative of nitric oxide, NO) and the production of tumor necrosis factor- $\alpha$ (TNF- $\alpha$ ). NO is a free radical with multiple biological functions that is overproduced by different cell types after an oxidative stress and/or inflammation induction evoked by NPs exposure. It is involved in immune response but, during a chronic inflammatory reaction, elevated levels of NO are found that became toxic for host cells. The role of NO in the cytotoxic immune response was first revealed by demonstrating the induction of the inducible NO Synthase (NOS, the enzyme responsible for NO synthesis and induced by oxidative stress), in target cells by immune cytokines (e.g. TNF- $\alpha$, etc.) and resulting in the apoptosis induction (Bogdan 2015).

Detection of tumor necrosis factor-alpha (TNF- $\alpha$ ) release was performed to evaluate the inflammatory effects as this cytokine represents important mediator of pulmonary inflammation in humans.

TNF- $\alpha$ is a pro-inflammatory cytokine involved in systemic inflammation, stimulating the acute phase reaction.

The control sample P25 induced a strong release of NO in BEAS-2B cells (Figure 4) in concentration dependent manner, while a much less effect, albeit significant, was observed after $\mathrm{TiO}_{2}-\mathrm{AA} \mathrm{TiO}_{2}-\mathrm{AB}$ and $\mathrm{TiO}_{2}-\mathrm{AO}$ cellular exposure. In particular, the exposure to 5.0 and $10 \mu \mathrm{g} / \mathrm{cm}^{2}$ of P25 lead to a 3 times higher releasing of NO than our synthesized samples.

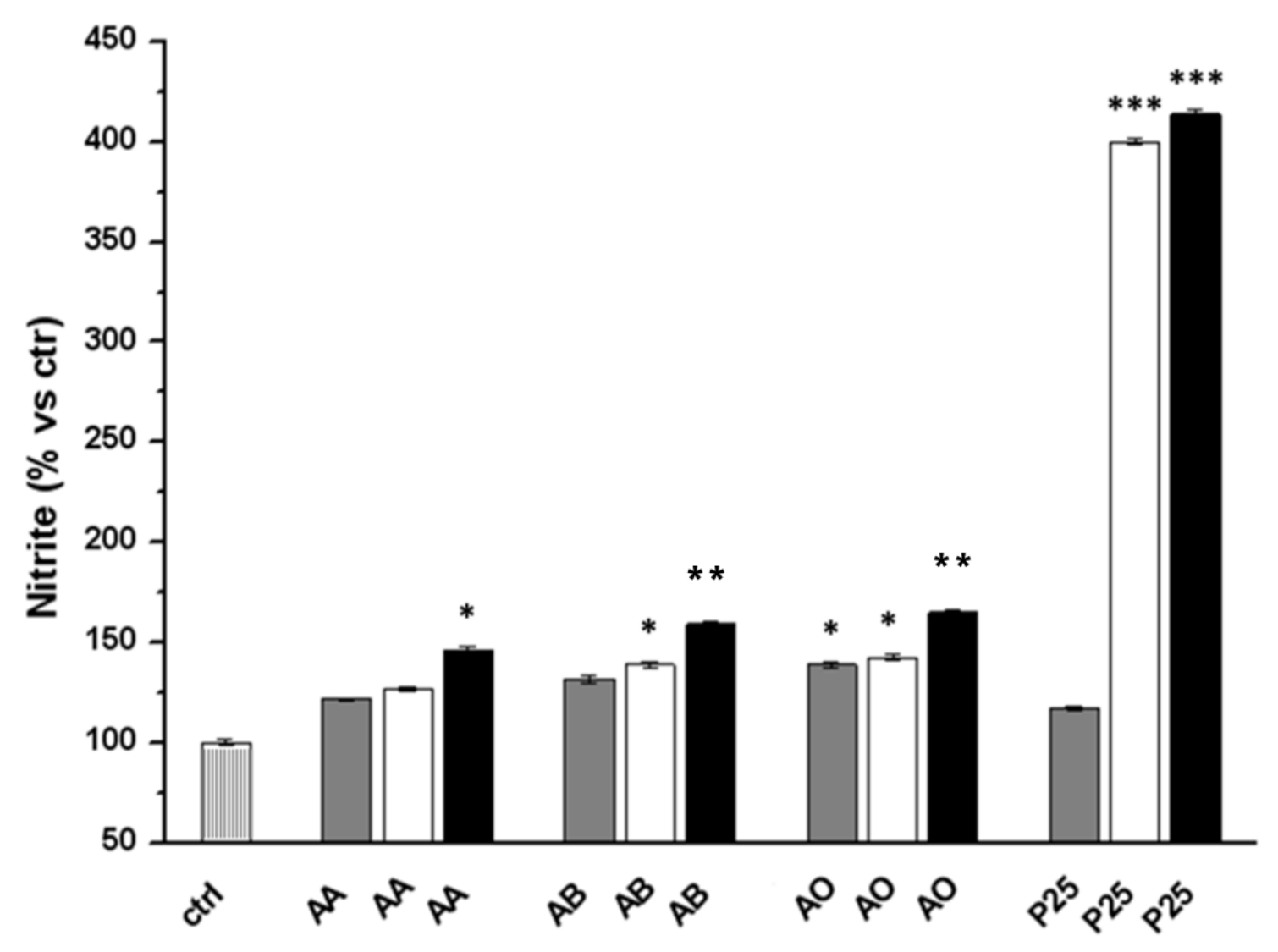


Figure 4: Effect of titanium dioxide nanoparticles on BEAS-2B for extracellular levels of nitrite. Cells were incubated with 1.0 (gray), 5.0 (white) and 10 (black) $\mu \mathrm{g} / \mathrm{cm}^{2}$ of the different $\mathrm{TiO}_{2}$ samples for 72 hours. Values are expressed as the mean \pm standard deviation of three independent experiments $(\mathrm{n}=3)$. The $95 \%$ confidence $(\mathrm{p}<0.05)$ was considered significant vs control (straight line) ${ }^{*} \mathrm{p}<0.05$ was considered significant. vs respective control: ${ }^{*} \mathrm{p}<0,01 ; * * \mathrm{p}<0,001 ; * * * \mathrm{p}<0.0001$

The accumulation of TNF- $\alpha$ concentration was significantly increased in a concentration dependent manner both for synthesized samples and for commercial one (Fig.5). For the lowest concentration tested of our samples there is no significant TNF- $\alpha$ production in comparison to the same tested concentration of P25. $\mathrm{TiO}_{2}-\mathrm{AA}$ did not elicit any effect to cells also at the other higher concentrations. $\mathrm{TiO}_{2}-\mathrm{AB}$ and $\mathrm{TiO}_{2}-\mathrm{AO}$ led to the production of this cytokine but the measured values are lower than those measured for P25.

A trend similar to NO release was observed, being $\mathrm{P} 25$ the most active while $\mathrm{TiO}_{2}$-AA did not elicit any effect to cells.

Note that cell-free tests aimed to reveal any interference of the particles with the assay reagents were performed (data not shown).

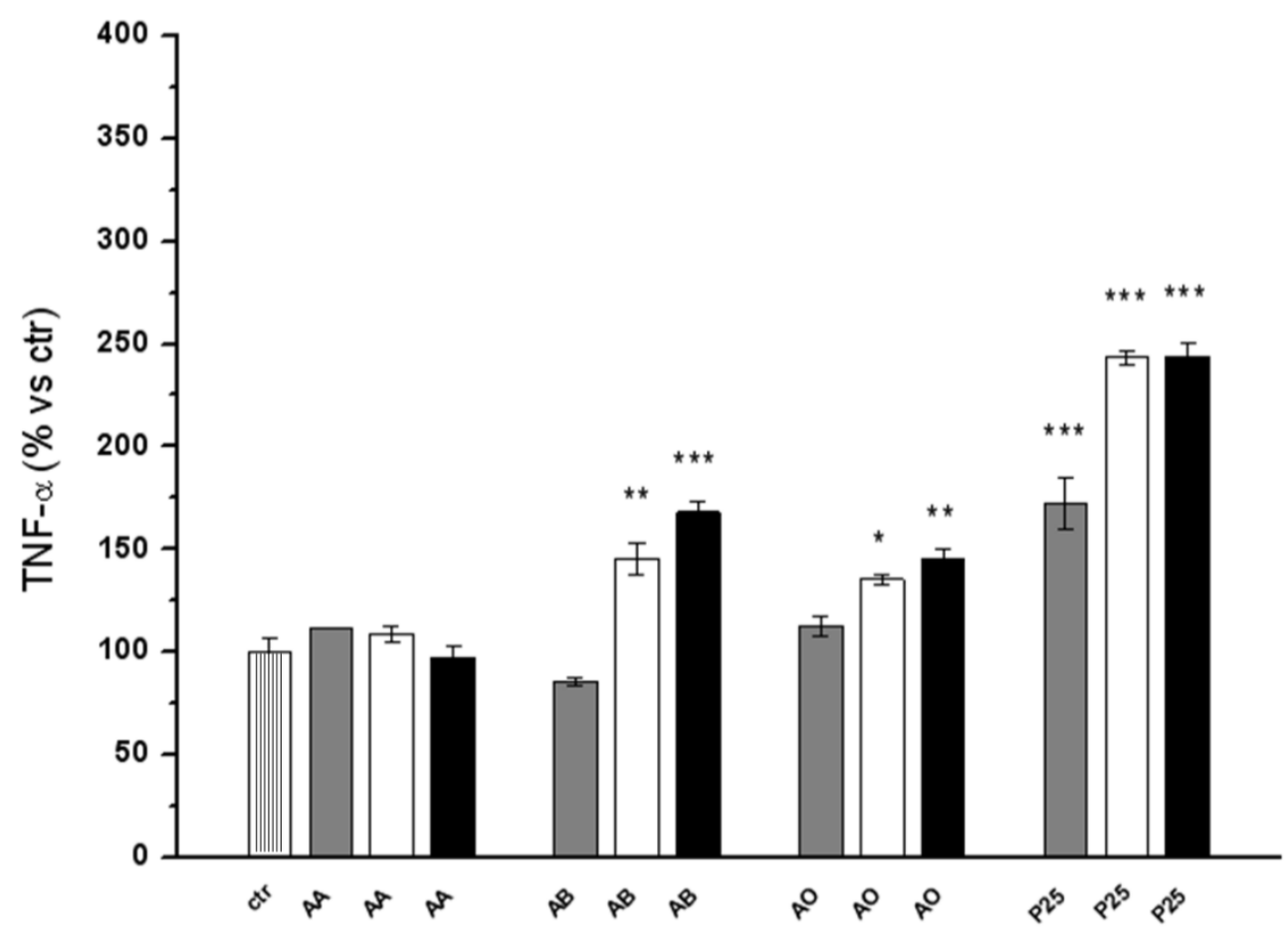

Figure 5: Effect of titanium dioxide nanoparticles on BEAS-2B for TNF- $\alpha$ production. Cells were incubated with 1.0 (gray), 5.0 (white) and 10 (black) $\mu \mathrm{g} / \mathrm{cm}^{2}$ of the different $\mathrm{TiO}_{2}$ samples for 72 hours.Values are expressed as the mean \pm standard deviation of three independent experiments $(n=3)$. The $95 \%$ confidence $(\mathrm{p}<0.05)$ was considered significant vs control (straight line). ${ }^{*} \mathrm{p}<0.05$ was considered significant. vs respective control: $* \mathrm{p}<0,01 ; * * \mathrm{p}<0,001 ; * * * \mathrm{p}<0.0001$.

\subsection{Oxidative stress}

To elucidate the role of oxidative stress in toxic effect evoked by nanoparticles, lipoperoxidation was evaluated by measuring the intracellular levels of TBARS, which are molecules (such as malonyldialdehyde and other aldehydes) produced by oxidative degradation of fatty acids. After a $72 \mathrm{~h}$ incubation, the generation of TBARS was not significantly increased in cells exposed both to synthetic $\mathrm{TiO}_{2}$, and P25 (see 
SM figure SM3) at $10 \mu \mathrm{g} / \mathrm{cm}^{2}$. The level of reduced glutathione (GSH), the most important intracellular antioxidant molecule, is a sensitive index of the efficiency of cellular antioxidant defenses and its decrease is a marker of oxidative stress. In our cellular model, GSH levels resulted decreased after incubation with $\mathrm{TiO}_{2}$ nanoparticles. However the differences observed between treated cells and controls were not statistically significant (see SM figure SM4).

\section{Discussion}

Recent studies provide strong evidence that nanoparticles can not only passively interact with cells(Nel, Xia et al. 2006; Thill, Zeyons et al. 2006; Auffan, Achouak et al. 2008; Gratton, Ropp et al. 2008), but also interfere with molecular processes that are essential for regulating cell functions(Jiang, KimBetty et al. 2008).

In the present study, we have investigated the photoactivity and the cellular toxicity of three $\mathrm{TiO}_{2}$ nanomaterials in anatase phase synthesized via a microwave-solvothermal route, in comparison to the known toxic Aeroxide P25, in terms of cytotoxicity and induction of oxidative stress and inflammatory markers evaluation.

Characterization in cell media showed little differences among samples in term of $\zeta$ potentialand dispersion state, but a smaller polydispersion index (PDI) with respect to P25. Under simulated solar illumination the samples showed a very little oxidative reactivity when compared with P25. The observed low oxidative reactivity may be relevant for ecotoxicity of the nanomaterials accidentally released in the environment during the life cycle of the composite. No reactivity was detected in dark conditions possibly thus excluding particle-derived ROS release in the body. Note however that the possible generation of superoxide radicals or singlet have not been assessed in the present study. In the case of nanoparticles doped with boron, a decrease in photoactivity was also observed. In this case, the effect should not be due to the presence of a coating, but rather to the inhibitory effect of boron. In fact, doping with boron was reported to both increase or decrease the photocatalytic activity of $\mathrm{TiO}_{2}$ depending upon the synthetic method used (Xu, Picca et al. 2013).

P25 appears clearly cytotoxic and induces an oxidative stress and an inflammatory response in our cellular model at relatively low doses. Ekstrand-Hammarström and co-workers previously found that Aeroxide P25 did not induce cytotoxic effect on BEAS-2B cells up to $200 \mu \mathrm{g} / \mathrm{mL}$ (Ekstrand-Hammarström 2012). Theirresults were in contrast with what found by Park and coworkers that reported a significant cytotoxicity already at $5 \mu \mathrm{g} / \mathrm{mL}$ (Park, Yi et al. 2008). The different results were suggested to be due to the absence of serum in the cell media (Ekstrand-Hammarström 2012). Our results support the hypothesis since the experiments were performed in RPMI supplemented with 10\% FBS, the same conditions used by Park and co-workers.

Albeit cytotoxic and pro-inflammatory in BEAS-2B cells, P25 did not induce lipoperoxidation in our cellular model, suggesting a ROS generation by independent mechanism. This is consistent with the previous studies sinceROS generation was reported to be induced by P25 on BEAS-2B cells (Park, Yi et al. 2008; Ekstrand- 
Hammarström, Akfur et al. 2011) but at higher doses. A possible mechanism involves TNF $\alpha$ release, that can stimulate signalling pathways associated to the inflammatory reaction, such as Jak/STAT(Rauch, Muller et al. 2013), which can increase cytokines production (IL-4, IL-6, IL-8) and oxidative stress, the latter via inducing NO and reactive nitrogen species (RNS) production. Therefore, RNS may induce redox-sensitive transcription factors such as NF-kB (Haddad 2002), which in turn may contribute to increase the cross-talk between oxidative stress and inflammation in the lung, by promoting further cytokines and NO production. Conversely to Aeroxide P25, the modified $\mathrm{TiO}_{2}$ samples exhibited low cytotoxicity as measured by the LDH assay toward BEAS-2B cells. However, cells exposed to powders showed release of NO and TNF $\alpha$, depending upon the kind of moieties at the surfaceof the nanoparticles. In fact, while $\mathrm{TiO}_{2}-\mathrm{AA}$ was inert at the tested doses, $\mathrm{TiO}_{2}-\mathrm{AB}$ and $\mathrm{TiO}_{2}-\mathrm{AO}$ induced the release of $\mathrm{NO}$ and $\mathrm{TNF} \alpha$, albeit at much less extent than P25.

The data here reported overall suggest a toxicity of the $\mathrm{TiO}_{2}$ samples much lower than $\mathrm{P} 25, \mathrm{TiO}_{2}$ - $\mathrm{AA}$ being the less toxic among the synthesized samples. Based on the wide literature on this topic, this finding may be related to differences in physico-chemical properties among samples. One possible reason may be the different dispersion state of the samples by respect to P25 that, in turn, may affect the internalization in cells (Ekstrand-Hammarström, Akfur et al. 2011). Another property that modulate the toxic effects is the crystalline phase: there are several studies reporting P25 to be more toxic than the other polymorphs (Gerloff, Fenoglio et al. 2012), despite the presence of the rutile phase, generally considered less toxic (Sayes, Wahi et al. 2006). On the other hand Gurret al. reported that an anatase sample, having a primary particle size similar to those tested here, induced oxidative DNA damage, lipid peroxidation, and micronuclei formation, and increased hydrogen peroxide and nitric oxide production in BEAS-2B cells(Gurr, Wang et al. 2005). The role of surface area in $\mathrm{TiO}_{2}$ toxicity is generally accepted (Oberdörster 2000; Singh, Shi et al. 2006). However, in the present case, the $\mathrm{TiO}_{2}$ samples exhibit a surface area higher than $\mathrm{P} 25$, but a lower toxicity. The samples tested here are slightly different in terms of shape of the primary particles. Shape, is considered a determinant of toxicity(Fadeel, Xue et al. 2010). However previous reports did not find any correlation among shape and toxicity of $\mathrm{TiO}_{2} \mathrm{NP}$ (Ravenzwaay, Landsiedel et al. 2009). Finally, as suggested by the $\zeta$-potential values recorded in water, all samples exhibit acidic species at the surface. These species may be responsible of both the reduced oxidative photo-reactivity and toxicity by forming a coating around the particles. Since coatings or adsorbed species have been previously reported to inhibits or modify the surface reactivity (Brezova, Gabcova et al. 2005; Sayes, Wahi et al. 2006; Carlotti, Ugazio et al. 2009; Tiano, Armeni et al. 2010; Shi 2013; Ghiazza, Alloa et al. 2014) and possibly the toxicity of $\mathrm{TiO}_{2}$ a major role of surface chemistry in the encountered differences may be hypothesized.

\section{Conclusion}

In conclusion the modified $\mathrm{TiO}_{2}$ samples appear to have a low photoreactivity and to elicit low or negligible toxic effects on human bronchial epithelial cells depending upon the kind of synthetic method used. Albeit further studies will be needed to fully assess the safety of these intermediates, the present data represent a 
first indication of low toxicity, the toxic effect elicited by the powders being much lower than the reference material AeroxideP25, already known as cytotoxic.

\section{Acknowledgements}

This work was supported by the PON, prot. n. 84/Ric. Del 2 marzo 2012 NAnoMAteriali per l'edilizia SosTEnibile (NAMASTE) prot. PON04a3_00107 CUP: B35I12000100005.

\section{References}

Auffan, M., W. Achouak, et al. (2008). "Relation between the Redox State of Iron-Based Nanoparticles and Their Cytotoxicity toward Escherichia coli." Environmental Science \& Technology 42(17): 67306735.

Bhattacharya, K. (2009). "Titanium dioxidenanoparticles induce oxidative stress and DNA-adduct formation but not DNA-breakage in human lung cells." Part. Fibre Toxicol. 6: 17.

Bogdan, C. (2015). "Nitric oxide synthase in innate and adaptive immunity: an update." Trends Immunol 36(3): 161-78.

Brezova, V., S. Gabcova, et al. (2005). "Reactive oxygen species produced upon photoexcitation of sunscreens containing titanium dioxide (an EPR study)." J Photochem Photobiol B 79(2): 121-34.

Carlotti, M. E., E. Ugazio, et al. (2009). "Role of particle coating in controlling skin damage photoinduced by titania nanoparticles." Free radical research 43(3): 312-322.

Carlucci, C., B. Scremin, et al. (2014). "Microwave-Assisted Synthesis of Boron-Modified TiO2 Nanocrystals." Inorganics 2(2): 264-277.

Carlucci, C., H. Xu, et al. (2014). "Selective synthesis of TiO2 nanocrystals with morphology control with the microwave-solvothermal method." CrystEngComm 16(9): 1817-1824.

Carlucci, C., H. Xu, et al. (2014). "Controllable One-Pot Synthesis of Anatase TiO<sub $>2</$ sub $>$ Nanorods with the Microwave-Solvothermal Method." Science of Advanced Materials 6(8): 1668-1675.

Chen, H. W. (2006). Titanium dioxide nanoparticles induce emphysema-like lung injury in mice, The Federation. 20.

Ciccarella Giuseppe, C. C. (2014). "TiO2 nanoparticles synthesis, under shape and size control by means of microwave reaction." Patent 29.10.2014, EP2796414A1.

Clemente, Z., V. L. Castro, et al. (2014). "Toxicity assessment of TiO(2) nanoparticles in zebrafish embryos under different exposure conditions." Aquat Toxicol 147: 129-39.

Corazzari, I., S. Livraghi, et al. (2012). "Inactivation of TiO2 nano-powders for the preparation of photostable sunscreens via carbon-based surface modification." Journal of materials chemistry 22(36): 19105-19112.

Dunford, R., A. Salinaro, et al. (1997). "Chemical oxidation and DNA damage catalysed by inorganic sunscreen ingredients." FEBS Letters 418(1-2): 87-90.

Ekstrand-Hammarström, B., C. M. Akfur, et al. (2011). "Human primary bronchial epithelial cells respond differently to titanium dioxide nanoparticles than the lung epithelial cell lines A549 and BEAS-2B." Nanotoxicology 6(6): 623-634.

Fadeel, B., D. Xue, et al. (2010). "Programmed cell clearance: molecular regulation of the elimination of apoptotic cell corpses and its role in the resolution of inflammation." Biochemical and biophysical research communications 396(1): 7-10.

Falck, G. C. (2009). "Genotoxic effects of nanosized and fine TiO2." Human \& experimental toxicology 28: 339-352.

Fenoglio, I., J. Ponti, et al. (2013). "Singlet oxygen plays a key role in the toxicity and DNA damage caused by nanometric TiO2 in human keratinocytes." Nanoscale 5(14): 6567-76. 
Foster, K. A., F. Galeffi, et al. (2006). "Optical and pharmacological tools to investigate the role of mitochondria during oxidative stress and neurodegeneration." Prog Neurobiol 79(3): 136-71.

Frohlich, E. and S. Salar-Behzadi (2014). "Toxicological assessment of inhaled nanoparticles: role of in vivo, ex vivo, in vitro, and in silico studies." Int J Mol Sci 15(3): 4795-822.

Gerloff, K., I. Fenoglio, et al. (2012). "Distinctive toxicity of TiO2 rutile/anatase mixed phase nanoparticles on Caco-2 cells." Chemical research in toxicology 25(3): 646-655.

Ghiazza, M., E. Alloa, et al. (2014). "Inhibition of the ROS-mediated cytotoxicity and genotoxicity of nano$\mathrm{TiO} 2$ toward human keratinocyte cells by iron doping." Journal of nanoparticle research : an interdisciplinary forum for nanoscale science and technology 16(2).

Ghigo, D., E. Aldieri, et al. (1998). "Chloroquine stimulates nitric oxide synthesis in murine, porcine, and human endothelial cells." J Clin Invest 102(3): 595-605.

Gratton, S. E. A., P. A. Ropp, et al. (2008). "The effect of particle design on cellular internalization pathways." Proceedings of the National Academy of Sciences 105(33): 11613-11618.

Gurr, J. R., A. S. Wang, et al. (2005). "Ultrafine titanium dioxide particles in the absence of photoactivation can induce oxidative damage to human bronchial epithelial cells." Toxicology 213(1-2): 66-73.

Haddad, J. J. (2002). "Redox regulation of pro-inflammatory cytokines and IKB- $\alpha / \mathrm{NF}-\mathrm{KB}$ nuclear translocation and activation." Biochemical and Biophysical Research Communications 296(4): 847856.

Jarvinen, M. (1993). "Application of symmetrized harmonics expansion to correction of the preferred orientation effect." Journal of Applied Crystallography 26(4): 525-531.

Jiang, J., G. Oberdörster, et al. (2009). "Characterization of size, surface charge, and agglomeration state of nanoparticle dispersions for toxicological studies." Journal of Nanoparticle Research 11(1): 77-89.

Jiang, W., Y. S. KimBetty, et al. (2008). "Nanoparticle-mediated cellular response is size-dependent." Nat Nano 3(3): 145-150.

Johnston, H. J. (2009). "Identification of the mechanisms that drive the toxicity of TiO2 particulates: the contribution of physicochemical characteristics." Part. Fibre Toxicol. 6: 33.

Jugan, M. L. (2012). "Titanium dioxide nanoparticles exhibit genotoxicity and impair DNA repair activity in A549 cells." Nanotoxicology 6: 501-513.

Ma, H., A. Brennan, et al. (2011). "Phototoxicity of TiO2 nanoparticles under solar radiation to two aquatic species: Daphnia magna and Japanese medaka." Environmental toxicology and chemistry 31(7): 1621-1629.

Marucco, A., F. Catalano, et al. (2015). "Possible Chemical Source of Discrepancy between in Vitro and in Vivo Tests in Nanotoxicology Caused by Strong Adsorption of Buffer Components." Chemical research in toxicology 28(1): 87-91.

Marucco, A., F. Turci, et al. (2013). "Hydroxyl density affects the interaction of fibrinogen with silica nanoparticles at physiological concentration." Journal of colloid and interface science 419: 86-94.

Moschini, E. (2013). "The modality of cell-particle interactions drives the toxicity of nanosized $\mathrm{CuO}$ and $\mathrm{TiO}_{2}$ in human alveolar epithelial cells." Toxicology Letters 222: 102-116.

Nel, A., T. Xia, et al. (2006). "Toxic potential of materials at the nanolevel." Science 311(5761): 622-7.

Oberdörster, G. (2000). "Pulmonary effects of inhaled ultrafine particles." International Archives of Occupational and Environmental Health 74(1): 1-8.

Oberdörster, G., A. Elder, et al. (2009). "Nanoparticles and the Brain: Cause for Concern?" Journal of Nanoscience and Nanotechnology 9(8): 4996-5007.

Park, E.-J., J. Yi, et al. (2008). "Oxidative stress and apoptosis induced by titanium dioxide nanoparticles in cultured BEAS-2B cells." Toxicology Letters 180(3): 222-229.

Park, E. J. (2008). "Oxidative stress and apoptosis induced by titanium dioxide nanoparticles in cultured BEAS-2B cells." Toxicology Letters 180: 222-229.

Petkovic, J. (2011). "DNA damage and alterations in expression of DNA damage responsive genes induced by TiO2 nanoparticles in human hepatoma HepG2 cells." Nanotoxicology 5: 341-353.

Polimeni, M., E. Gazzano, et al. (2008). "Quartz inhibits glucose 6-phosphate dehydrogenase in murine alveolar macrophages." Chem Res Toxicol 21(4): 888-94. 
Prasad, R. Y. (2013). "Effect of treatment media on the agglomeration of titanium dioxide nanoparticles: impact on genotoxicity, cellular interaction, and cell cycle." ACS Nano 7: 1929-1942.

Rauch, I., M. Muller, et al. (2013). "The regulation of inflammation by interferons and their STATs." JAKSTAT 2(1): e23820.

Ravenzwaay, B., R. Landsiedel, et al. (2009). "Comparing fate and effects of three particles of different surface properties: nano-TiO(2), pigmentary TiO(2) and quartz." Toxicology letters 186(3): 152-159.

Sayes, C. M., R. Wahi, et al. (2006). "Correlating nanoscale titania structure with toxicity: a cytotoxicity and inflammatory response study with human dermal fibroblasts and human lung epithelial cells." Toxicol Sci 92(1): 174-85.

Shi, H. (2013). "Titanium dioxide nanoparticles: a review of current toxicological data." Part. Fibre Toxicol. 10: 15.

Shi, Y. (2010). "Titanium dioxide nanoparticles cause apoptosis in BEAS-2B cells through the caspase 8/t-Bid-independent mitochondrial pathway." Toxicology Letters 196: 21-27.

Singh, S., T. Shi, et al. (2006). "Endocytosis, oxidative stress and IL-8 expression in human lung epithelial cells upon treatment with fine and ultrafine TiO2: role of the specific surface area and of surface methylation of the particles." Toxicology and applied pharmacology 222(2): 141-151.

Soto, K. (2007). "Cytotoxic effects of aggregated nanomaterials 3 . " Acta biomaterialia 3(3): 351-358.

Soto, K. F. (2005). "Comparative in vitro cytotoxicity assessment of some manufacturednanoparticulate materials characterized by transmissionelectron microscopy." Journal of nanoparticle research : an interdisciplinary forum for nanoscale science and technology 7(2-3): 145-169.

Thill, A., O. Zeyons, et al. (2006). "Cytotoxicity of CeO2 Nanoparticles for Escherichia coli. Physico-Chemical Insight of the Cytotoxicity Mechanism." Environmental Science \& Technology 40(19): 6151-6156.

Tiano, L., T. Armeni, et al. (2010). "Modified TiO(2) particles differentially affect human skin fibroblasts exposed to UVA light." Free Radic Biol Med 49(3): 408-15.

Vandeputte, C., I. Guizon, et al. (1994). "A microtiter plate assay for total glutathione and glutathione disulfide contents in cultured/isolated cells: performance study of a new miniaturized protocol." Cell Biology and Toxicology 10(5-6): 415-421.

Warheit, D. B. (2007). "Pulmonary toxicity study in rats with three forms of ultrafine-TiO2 particles: Differential responses related to surface properties." Toxicology (Amsterdam) 230(1): 90-104.

Warheit, D. B., P. J. A. Borm, et al. (2007). "Testing Strategies to Establish the Safety of Nanomaterials: Conclusions of an ECETOC Workshop." Inhalation Toxicology 19(8): 631-643.

Wiles, D. B. and R. A. Young (1981). "A new computer program for Rietveld analysis of X-ray powder diffraction patterns." Journal of Applied Crystallography 14(2): 149-151.

Xu, H., C. Carlucci, et al. (2014). "Synthesis of Ultrafine Anatase Titanium Dioxide (TiO<sub $>2</$ sub $>$ ) Nanocrystals by the Microwave-Solvothermal Method." Journal of Nanoengineering and Nanomanufacturing 4(1): 28-32.

Xu, H., R. A. Picca, et al. (2013). "Nonhydrolytic Route to Boron-Doped TiO2 Nanocrystals." European Journal of Inorganic Chemistry 2013(3): 364-374.

Xue, C. (2010). "Nano titanium dioxide induces the generation of ROS and potential damage in HaCaT cells under UVA irradiation." J. Nanosci. Nanotechnol. 10: 8500-8507.

Yano, E. (1988). "Mineral fiber-induced malondialdehyde formation and effects of oxidant scavengers in phagocytic cells." International Archives of Occupational and Environmental Health 61(1-2): 19-23. 


\title{
Surface reactivity and in vitro toxicity on human bronchial epithelial cells (BEAS-2B)of nanomaterials intermediates of the production of titania-based composites
}

\author{
Viviana Vergaro $^{\mathrm{a}, \mathrm{b}}$, Elisabetta Aldieri ${ }^{\mathrm{c}, \mathrm{d}}$, Ivana Fenoglio $^{\mathrm{d}, \mathrm{e}_{*}}$, Arianna Marucco $^{\mathrm{d}, \mathrm{e}}$, Claudia Carlucci ${ }^{\mathrm{f}}$, \\ Giuseppe Ciccarella $\mathrm{a}^{\mathrm{a}, \mathrm{b}_{*}}$
}

${ }^{a}$ Biological and Environmental Sciences Department, University of Salento, Via Monteroni 73100 Lecce, Italy

${ }^{\mathrm{b}}$ Istituto di Nanotecnologia (NANOTEC) University of Salento, Via Monteroni 73100 Lecce, Italy

${ }^{c}$ Department of Oncology, University of Torino, Italy

${ }^{\mathrm{d}}$ Department of Chemistry and NIS - Nanostructured Interfaces and Surfaces, University of Torino, Italy

e، 'G. Scansetti', Interdepartmental Centre for Studies on Asbestos and other Toxic Particulates, University of Torino, Italy,

${ }^{\mathrm{f}}$ Department of Chemistry, University of Bari, Via Orabona 4, 70126 Bari, Italy

Contents:

1. $\zeta$ - potentialmeasurements

2. FT-IR Spectra

3. TBARS

4. GSH 

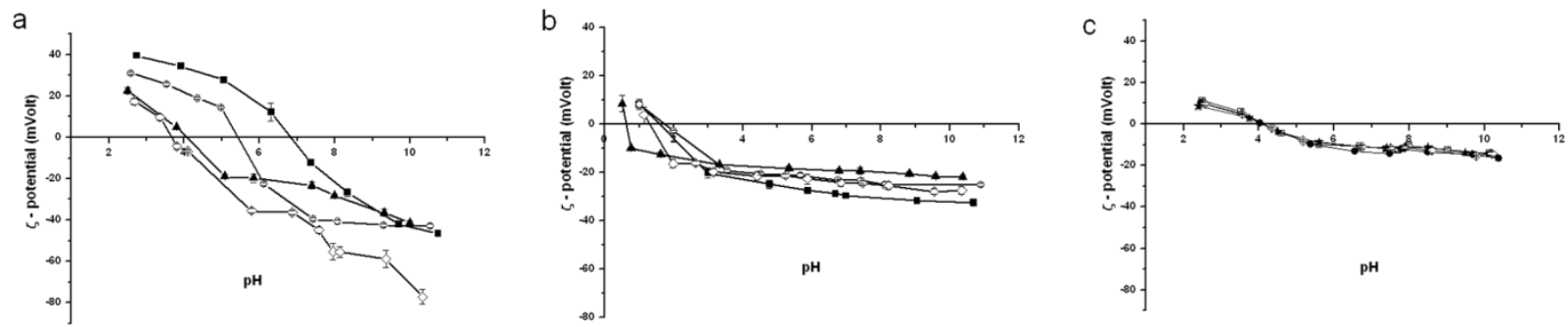

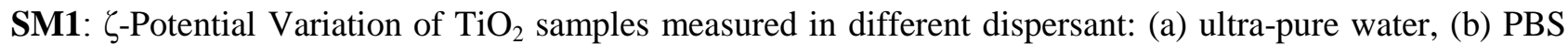
buffer and (c) RPMI culture media. The curves are measured after the suspension of samples nanoparticles, TA (circle), TO (rhombus), TB (star) and P25 (square) in the different solutions after 2 min of sonication. The acquisition of these curves is repeated for three times. 


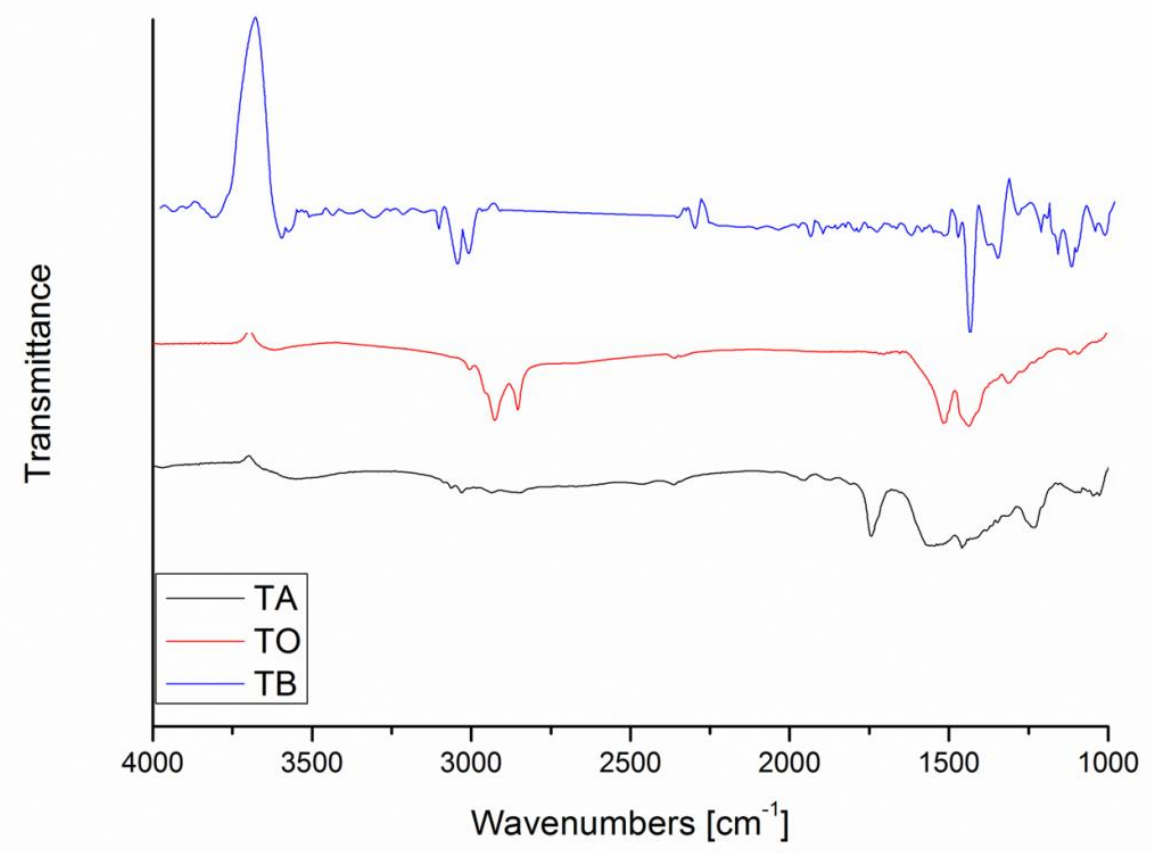

SM2: FT-IR Spectra of TA (black) TO (red) and TB (blu) 


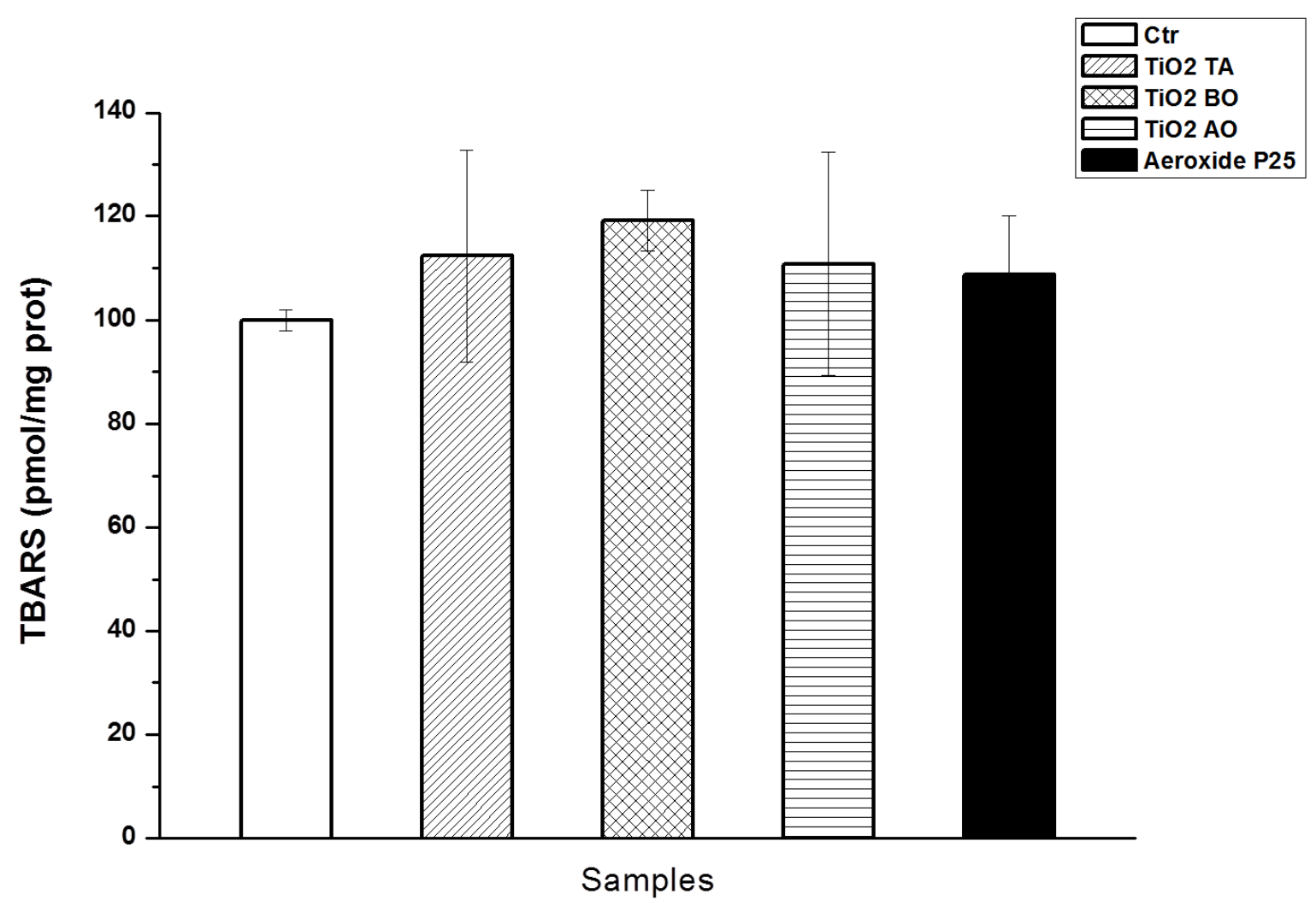

SM3: Effect of TiO2 NPs on the production of thiobarbituric acid reactive substances (TBARS) in BEAS-2B cells. Cells were incubated for $72 \mathrm{~h}$ in the absence (ctrl) or presence of $10 \mu \mathrm{g} / \mathrm{cm}^{2}$ of commercial Aeroxide $\mathrm{P} 25$ or synthetic $\mathrm{TiO}_{2} \mathrm{NPs}$ (Ta, TB and TO). Values are expressed as the mean and standard deviation, $\mathrm{n}=3$. The 95\% confidence $(\mathrm{p}<0.05)$ was considered significant vs control. There are no differences statistically significant. 


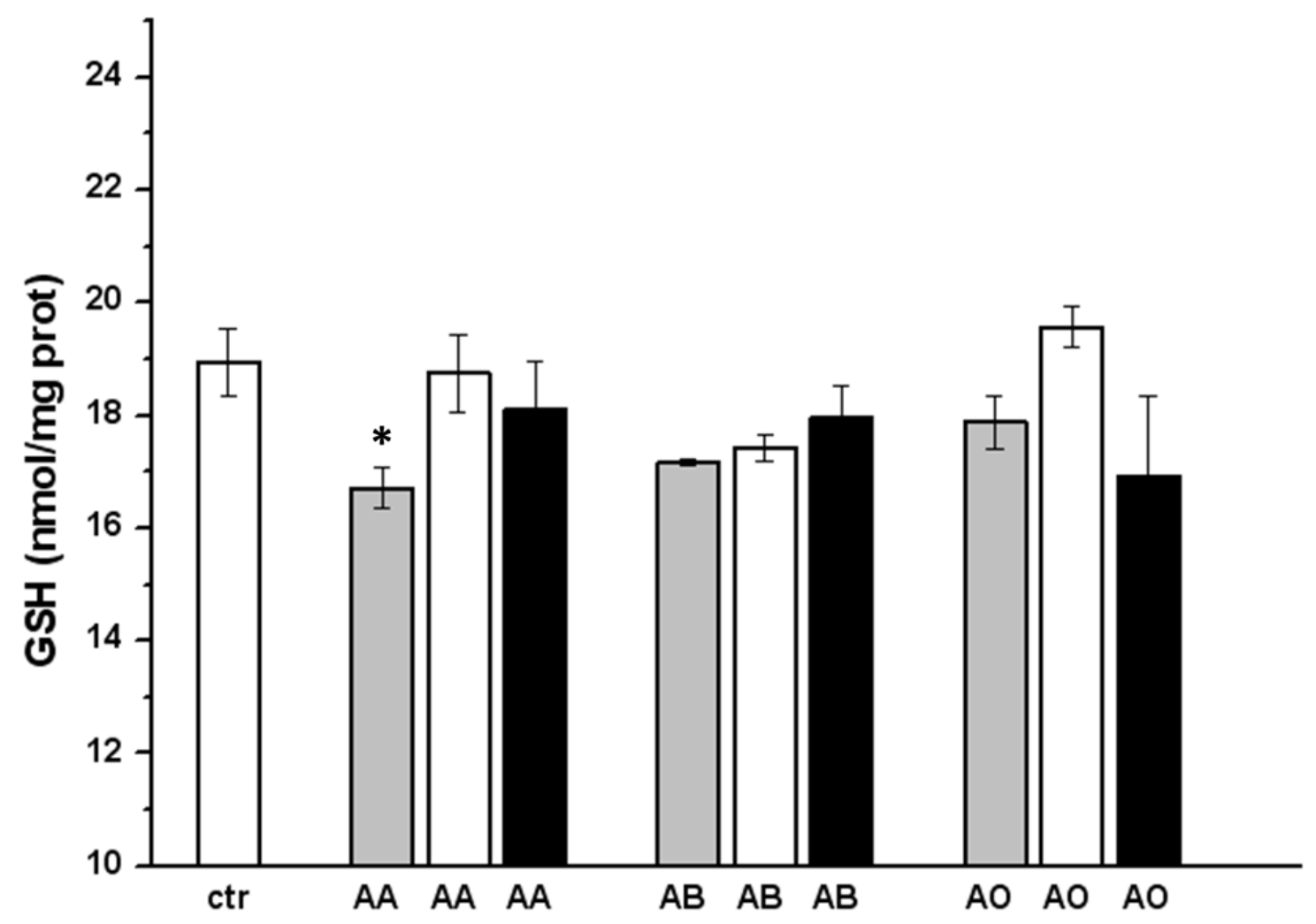

SM4: Effect of $\mathrm{TiO}_{2}$ NPs on the intracellular levels of reduced (GSH) in BEAS-2B cells. Cells were incubated for $72 \mathrm{~h}$ in the absence (ctrl) or presence of 1 (grey), 5 (white) or 10 (black) $\mu \mathrm{g} / \mathrm{cm}^{2}$ of Aeroxide $\mathrm{P} 25$ or synthetic $\mathrm{TiO}_{2} \mathrm{NPs}(\mathrm{AA}, \mathrm{AB}$ and $\mathrm{AO})$. Values are expressed as the mean and standard deviation, $\mathrm{n}=$ 3. The $95 \%$ confidence $(\mathrm{p}<0.05)$ was considered significant vs control. There are no differences statistically significant. 